(A)

Effect of gene family membership on topological properties of the three networks
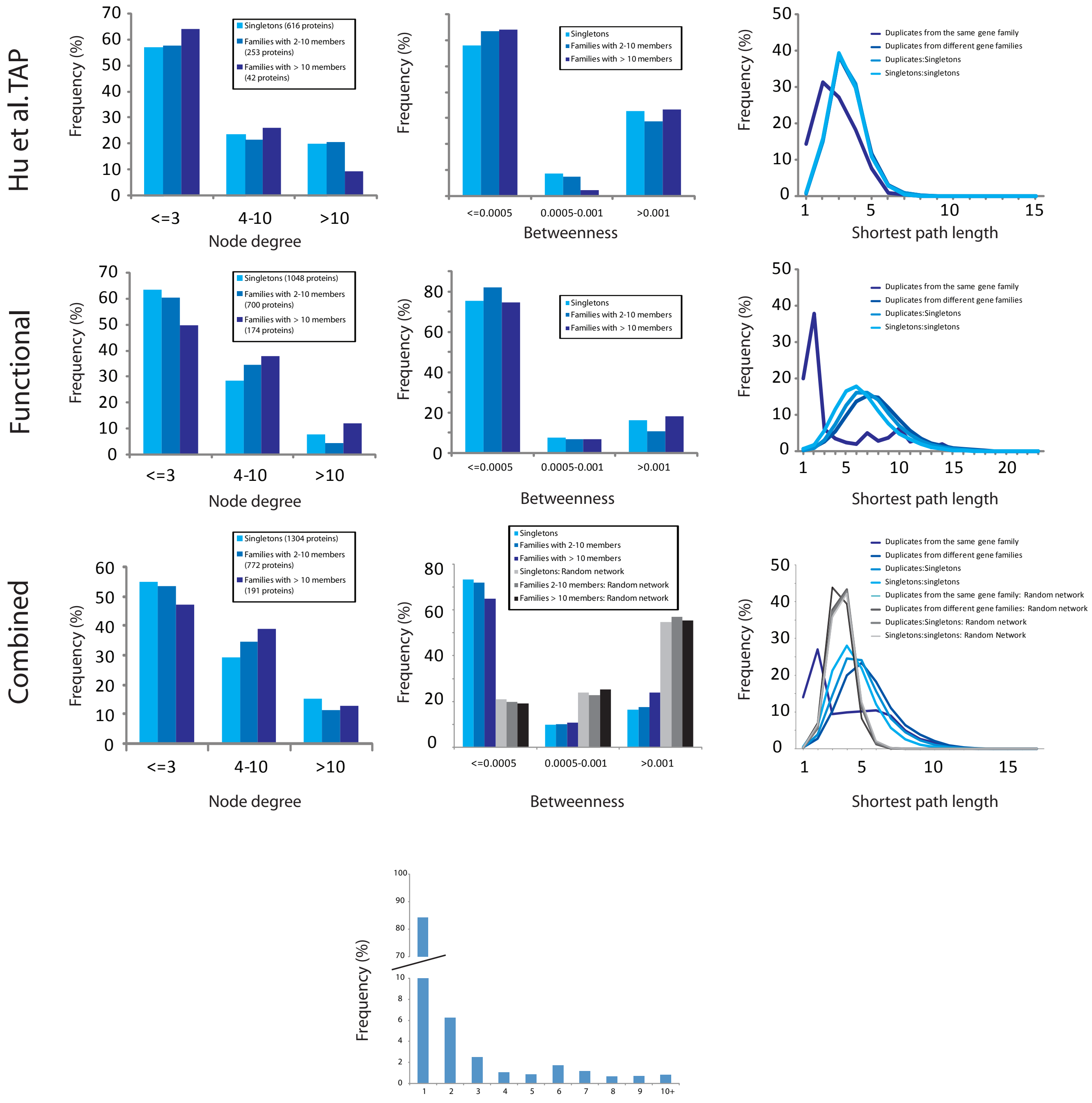

Number of interactions with the same gene family (combined network) 
(B)

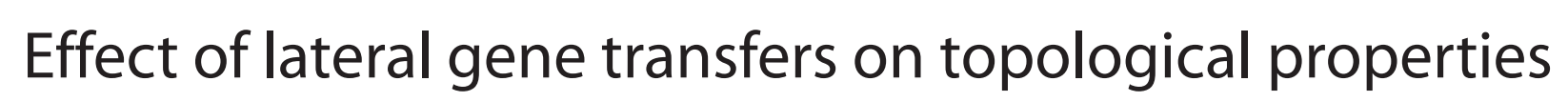

\section{of the three networks}
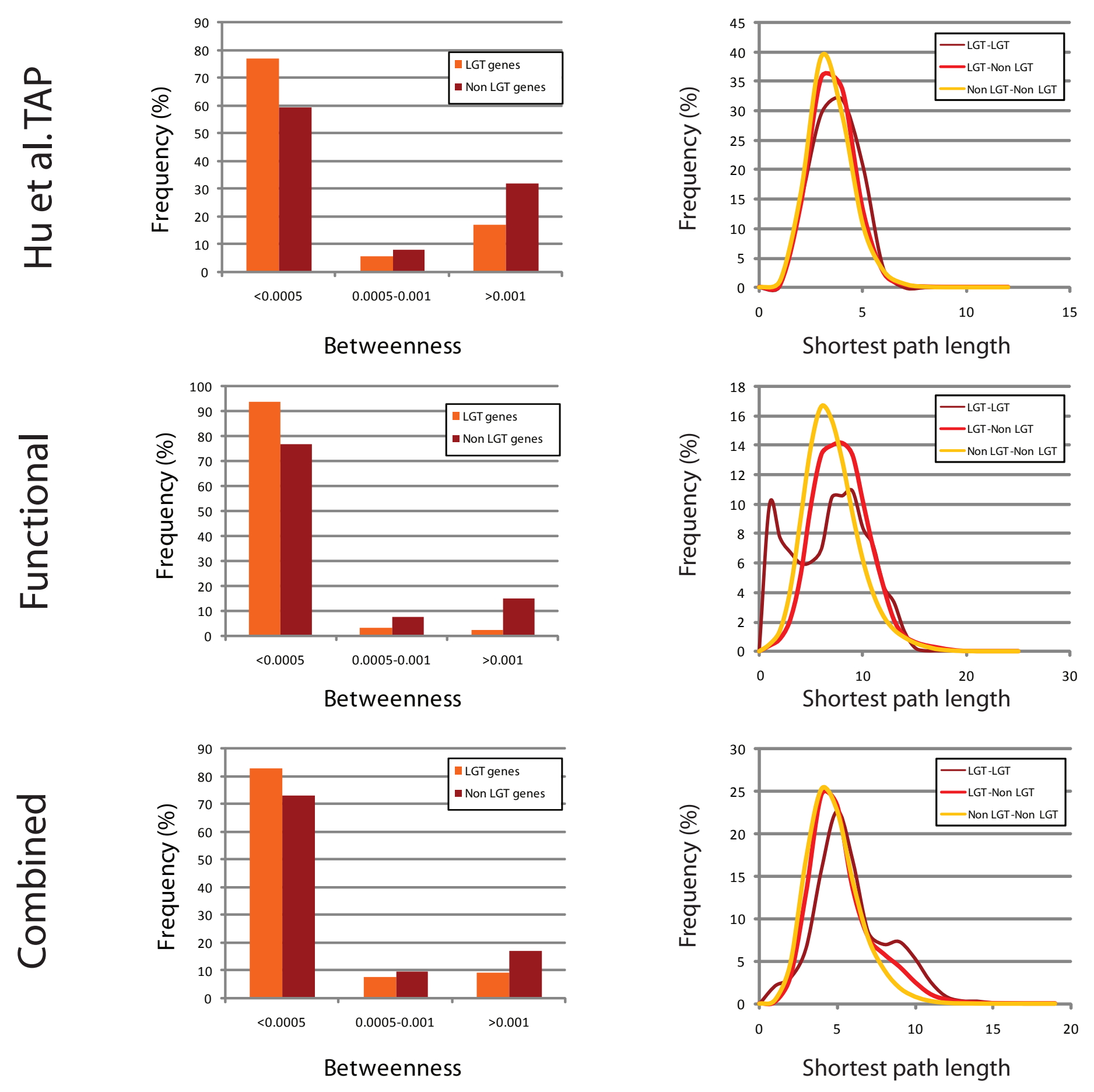